\title{
ESTUDO COMPARATIVO DE MOTORES DIESEL MARÍTIMOS ATRAVÉS DA ANÁLISE DE LUBRIFICANTES USADOS E ENGENHARIA DE CONFIABILIDADE
}

\author{
Oberdan Carrasco Nogueira ${ }^{11}$ \\ Mauro de Vasconcellos Real
}

\begin{abstract}
Resumo: O estudo apresenta a comparação de desempenho operacional de motores de combustão principais de embarcaçóes de suporte a plataformas de petróleo, utilizando dados de desgaste de componentes dos motores obtidos através das análises dos lubrificantes em operação nos mesmos e modelagem estatística do comportamento de falhas em função do tempo de operação dos equipamentos. Primeiramente efetuouse o estudo dos resultados das análises dos lubrificantes em uso nos motores, obtendo as distribuiçóes de probabilidade dos tempos de falhas da vida para os motores dois-tempos e quatro-tempos. Após esta etapa, realizou-se a modelagem dos motores, utilizando Distribuição de Weibull e utilizando a técnica de Diagrama de Blocos, determinando o comportamento dos tempos de falhas de cada subsistema, e posteriormente, dos equipamentos, obtendo-se os correspondentes parâmetros das distribuiçóes. De posse dessas informaçóes, foram determinados os intervalos de tempo correspondentes a um nível requerido de confiabilidade, obtendo consequentemente intervalos ótimos para intervençôes de manutenção preventiva.
\end{abstract}

Palavras-chave: Confiabilidade, Lubrificação, Motor Diesel, Manutenção.

\begin{abstract}
The article shows the operational performance comparison between Diesel Marine Engines used as main propulsion systems of the Platform Supply Vessels, using information about the wear of the components of the engines, gotten through Predictive Analysis Database of the lubricant used in these engines, and applying the Statistical Methodology of the failures-time behavior related the lifetime them. Once, the study of the predictive lubricant analysis results in use in these engines was done, classifying them according behavior, origin and wear level, obtain failure-time behavior related the lifetime of the engines, using Weibull distribution. After, it was done, using the Blocks Diagram, the model of the engines through its components, getting the failure-time behavior for each component, end finally, for two-stroke and four-stroke diesel engine with its distribution parameters. With these information, for a reliability level required, has gotten the lifetime corresponding at this reliability level, and the optimal time for the preventive maintenance actions.
\end{abstract}

Keywords: Reliability, Lubricant, Diesel engine, Maintenance

\footnotetext{
Escola de Engenharia - FURG, Rio Grande, RS - oberdannogueira@furg.br

2 Escola de Engenharia - FURG, Rio Grande, RS - mauroreal@furg.br
} 


\section{INTRODUÇÁO}

Atualmente, com o crescimento da exploração e produção de petróleo no Brasil, se torna cada vez mais evidente a necessidade de elevadas disponibilidade e confiabilidade dos equipamentos envolvidos neste processo, desde as plataformas de petróleo, responsáveis pela extração do produto do subsolo, até os equipamentos de suporte às plataformas, sem os quais as operaçóes de extração não são possíveis.

Entre estes equipamentos de suporte as plataformas, em se tratando especificamente de extração de petróleo em águas profundas, encontram-se as chamadas embarcaçóes offshore supridoras de plataformas, mais comumente chamadas de embarcações tipo PSV (Platform Supply Vessel), projetadas para enfrentar condiçôes metrológicas adversas e responsáveis pelo transporte de carga (água, combustível, granéis sólidos, ferramentas, etc.) do continente para as unidades de produção de petróleo.

Diante da importância destes equipamentos para o processo, as grandes empresas que atuam neste segmento utilizam elevada tecnologia no que diz respeito à manutenção preventiva sistemática e preditiva, sendo o monitoramento dos equipamentos através da análise do lubrificante uma das principais ferramentas de manutenção preditiva em utilização atualmente, podendo ser associada a outras técnicas, tais como Videoscopia, Inspeção Sensitiva, entre outras.

Sobretudo na última década, alguns trabalhos vêm sendo desenvolvidos em âmbito global e nos mais variados segmentos, desde modelos acadêmicos até a análise de dados práticos de embarcaçóes da guarda costeira americana, porém todos com o objetivo de aumentar a confiabilidade e disponibilidade dos motores diesel marítimos, e utilizando como ferramentas principais os dados de manutenção dos equipamentos e os conceitos de engenharia de confiabilidade.

Considerando o cenário exposto acima, este trabalho tem como objetivo realizar a Análise de Confiabilidade dos Motores de Combustáo Principais (MCP) de embarcações do tipo PSV de uma determinada empresa do segmento, utilizando os resultados das análises dos lubrificantes em operação nos referidos motores, de modo a determinar o comportamento dos níveis de desgaste em função do tempo de operação.

Para tal estudo, serão utilizados conceitos de manutenção preditiva associados a análises probabilísticas, baseadas nos resultados dos níveis de metais encontrados nos lubrificantes operantes nos motores através do ensaio de Espectrometria por Plasma, técnica amplamente utilizada por empresas que prestam serviços de análise de lubrificantes usados.

\section{ANÁLISE E METODOLOGIA}

\section{OS EQUIPAMENTOS}

As embarcaçôes tipo PSV devem possuir alta capacidade de manobra e dimensóes que permitam o suprimento das unidades de produção de petróleo. Para atingir este objetivo, estes tipos de equipamento possuem lemes e hélices independentes, sendo estas acionadas por motores independentes, geralmente denominados Motor de Combustão Principal Boreste (MCP BE) e Motor de Combustáo Principal Bombordo (MCP $\mathrm{BB})$. Esta disposiçáo permite maior mobilidade da embarcação, tanto em deslocamento, quanto em aproximação para descarga. Outros recursos para melhorar a mobilidade destas embarcaçóes foram inseridos, conforme citado por Silveira [8], tais como impelidores laterais de popa (Stern Thruster) e de Proa (Bow Thruster), porém estes são considerados como motores auxiliares, e não apresentam o mesmo nível de criticidade para as embarcaçóes comparativamente aos motores de combustão principais.

É importante ressaltar que, apesar da embarcação apresentar dois motores de acionamento independentes, a falha de um destes motores levará a total perda de capacidade da embarcação de executar sua função.

Visando manter a uniformidade das condiçôes de contorno do problema, escolheram-se basicamente dois modelos de motores de combustão principal, tendo suas especificaçôes técnicas apresentadas na Tabela 1. 
Tabela 1 - Principais Especificaçóes Técnicas dos Motores de Combustão Principal

\begin{tabular}{|c|c|c|}
\hline $\begin{array}{c}\text { Especificações } \\
\text { Técnicas }\end{array}$ & $\begin{array}{c}\text { Caterpillar } \\
\text { MAK 9M- } \\
20\end{array}$ & $\begin{array}{c}\text { General } \\
\text { Motors EMD } \\
16 \text { 645E7 }\end{array}$ \\
\hline Combustível & $\begin{array}{c}\text { Diesel } \\
\text { Marítimo }\end{array}$ & $\begin{array}{c}\text { Diesel } \\
\text { Marítimo }\end{array}$ \\
\hline $\begin{array}{c}\text { Diesel } \\
\text { quatro- } \\
\text { tempos }\end{array}$ & $\begin{array}{c}\text { Diesel dois- } \\
\text { tempos }\end{array}$ \\
\hline nominal (HP) & 2330 & 2850 \\
\hline $\begin{array}{c}\text { Rotaçáo } \\
\text { nominal (RPM) }\end{array}$ & 1000 & 900 \\
\hline $\begin{array}{c}\text { No de Pistóes } \\
\text { Diâmetro do } \\
\text { cilindro (mm) }\end{array}$ & 300 & 230 \\
\hline $\begin{array}{c}\text { Curso do } \\
\text { Cilindro (mm) }\end{array}$ & 300 & 254 \\
\hline
\end{tabular}

\section{COMPONENTES E PARÂMETROS DE MONITORAMENTO}

Os motores de combustão interna, tanto marítimos quanto veículos comerciais ou fora de estrada, apresentam algumas características particulares e de extrema importância para a investigação de falhas por desgaste de componentes através da análise do lubrificante. Os principais componentes sujeitos a desgaste nestes motores estáo apresentados na Figura 2.

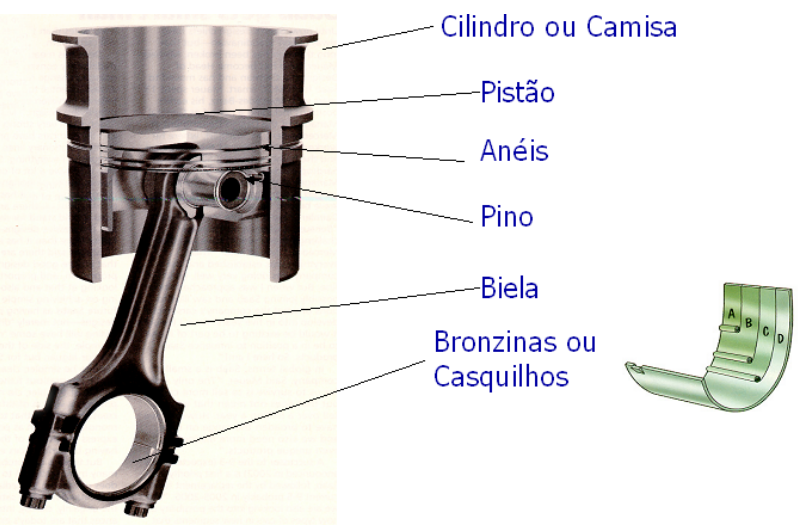

Figura 2 - Principais componentes de motores sujeitos a desgaste evidenciado pela análise do lubrificante

\section{Pistóes}

Os pistões são componentes responsáveis pelo recebimento da potência oriunda da queima na câmara de combustáo, transmitindo a energia em forma de movimento para o eixo virabrequim através das bielas. Os pistôes são fabricados utilizando ligas de Alumínio, e em casos de motores com problemas de combustão, podem sofrer aquecimentos localizados que poderão levar a trincas em sua face superior.

A presença de Alumínio nas análises de lubrificantes sugere a ocorrência de desgaste nestes componentes.

\section{Cilindros ou Camisas}

São componentes no qual ocorre o movimento do pistão no interior do motor e é o local onde ocorre a transferência de energia da combustão através do movimento do pistáo. As camisas geralmente são inseridas nos blocos dos motores como luvas, e devido ao fato de serem produzidas em aço, possuem como principal elemento químico detectável através das análises de lubrificantes o Ferro.

\section{Anéis de Segmento}

Sáo fixados em ranhuras feitas nos pistôes, e geralmente são inseridos três anéis por pistão. Os dois anéis superiores têm a incumbência de evitar perdas da potência geradas na combustão e impedir a passagem da mistura ar-combustível para o cárter através do espaçamento entre o pistão e o cilindro. $O$ terceiro anel tem a tarefa de selar a passagem de óleo do cárter para a câmara de combustão. Os anéis apresentam uma separação, que permite sua montagem no pistão e lhes dá uma tendência a se abrirem, pressionando-os contra a parede do cilindro e melhorando a vedação. Geralmente estes componentes são fabricados em Aços ao Cromo, e devido a este fator, a presença de Ferro e Cromo nas análises dos lubrificantes indica a presença de desgaste nos anéis.

\section{Biela}

Componente que transmite o movimento do pistão e a potência gerada pela combustão ao eixo de manivelas durante a expansão. A biela também permite movimento ao pistão durante os processos de exaustão, admissão e compressão. A biela consiste de uma haste com dois furos nos ex- 
tremos. É conectada ao pistão através de um pino que passa através do furo menor. $\mathrm{O}$ furo maior é constituído por um mancal fixado por parafusos, que envolve um dos pinos excêntricos do eixo de manivelas. No interior do furo maior da Biela estão dispostas as chamadas Bronzinas ou Casquilhos, componentes que atuam como bucha de deslizamento entre a biela e o eixo virabrequim, reduzindo o atrito mecânico entre os mesmos. Devido a serem produzidas com ligas de cobre, chumbo e estanho, são componentes de sacrifício (já que a biela e o eixo virabrequim em geral são constituídos de aço), e a presença destes elementos metálicos no lubrificante em uso indica o desgaste do componente.

Diante do exposto acima, para fins de simplificaçáo, a análise de lubrificantes considera o motor de combustáo interna dividido em duas partes principais: a "Parte Alta" e a "Parte Baixa" do motor, tendo como limite o anel de segmento responsável pela selagem do lubrificante na camisa. Considerando este aspecto, a Parte Alta do motor considera Cilindro, Pistóes, válvulas e anéis de segmento (incluindo o anel de vedação do óleo), e a Parte Baixa do motor engloba Biela, Eixo Virabrequim, Carter e Casquilhos.

É importante ressaltar que para cada um dos metais acima mencionados, existem limites toleráveis para a presença dos mesmos no lubrificante, de modo que, para fins de análise, estão sendo consideradas como falha a ocorrência de níveis de desgaste acima destes limites, para cada um dos elementos metálicos citados. Por isso, a partir de então, os níveis de desgastes dos motores em estudo serão classificados como desgaste na Parte Alta ou na Parte Baixa do motor, e não especificamente dos componentes mecânicos, para fins de simplificação do tratamento dos dados.

\section{ANÁLISE DE CONFIABILIDADE E MODELAGEM DO SISTEMA}

Segundo Information Science Consultant [2] e Reliasoft [9], a distribuição de Weibull é uma das distribuiçôes mais utilizadas na Engenharia de Confiabilidade. Devido a sua capacidade de mudar de forma dependendo da variaçáo do parâmetro $\beta$, permite modelar uma grande variedade de dados de vida. Esta distribuição de Probabilidade está sendo apresentada a seguir.

$$
\begin{aligned}
& f(T)=\frac{\beta}{\eta}\left(\frac{T-\gamma}{\eta}\right)^{\beta-1} e^{\left(\frac{T-\gamma}{\eta}\right)^{\beta}}(1), \text { onde } \\
& \beta: \text { Parâmetro de forma } \\
& \gamma: \text { Parâmetro de Localização } \\
& \eta \text { : Parâmetro de escala } \\
& \text { T: tempo (horas de operação) }
\end{aligned}
$$

Em função do parâmetro de forma é possível identificar a fase em que os equipamentos e seus componentes se encontram em termos de sua vida útil, conforme exposto por Lafraia [3]. Existem três fases distintas:

- Falhas Prematuras ou Mortalidade Infantil: falhas decorrentes ainda devido a problemas de projetos e start-up do equipamento. Nesta fase, a taxa de falhas do equipamento é decrescente.

- Período de Vida Útil: apresenta taxa de falhas constante, e corresponde ao período em que o equipamento apresenta apenas falhas aleatórias devido a problemas operacionais, falha humana, entre outras.

- Período de Final de Vida Útil: último estágio de comportamento da vida útil do equipamento, o qual apresenta taxa de falhas crescente, indicando o período de obsolescência do mesmo, sendo necessária intervenção para recuperação e aumento de sua confiabilidade.

Estas 3 fases formam uma curva muito utilizada na manutenção, denominada "Curva da Banheira”, apresentada na Figura 3, conforme apresentado por Aladon [1].

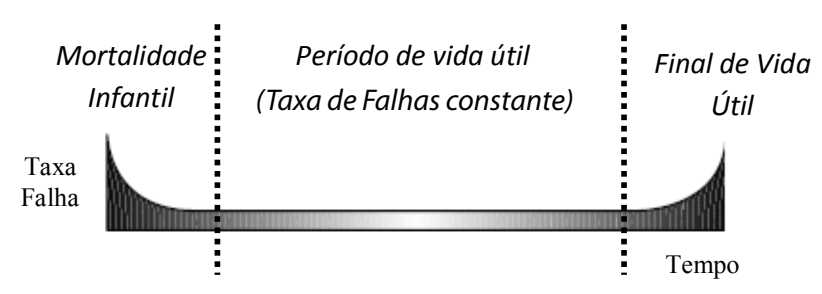

Figura 3 - Curva da Banheira

Levando em consideração as definições expostas acima, a Tabela 2 apresenta os tipos de distribuiçốes de aproximação e de falha em função do parâmetro de forma, conforme descrito em Reliasoft [7]. 
Tabela 2 - Distribuições e tipos de falhas em função do parâmetro de forma

\begin{tabular}{|c|c|c|}
\hline $\begin{array}{c}\text { Parâmetro } \\
\text { de forma } \beta\end{array}$ & Distribuição & $\begin{array}{c}\text { Tipo de } \\
\text { Falha }\end{array}$ \\
\hline 1,0 & Exponencial & Constante \\
\hline 1,0 a 2,5 & Aprox. Lognormal & Crescente \\
\hline 2,5 a 3,0 & Aprox. Normal & Crescente \\
\hline$>3,0$ & $\begin{array}{c}\text { Weibull com pouca } \\
\text { variabilidade }\end{array}$ & Crescente \\
\hline$<1,0$ & $\begin{array}{c}\text { Semelhante a } \\
\text { exponencial }\end{array}$ & Prematura \\
\hline
\end{tabular}

A Função Confiabilidade Weibull é definida por Reliasoft [8] através da seguinte equação

$$
R(T)=e^{-\left(\frac{T-\gamma}{\eta}\right)^{\beta}} \text { (2), onde }
$$

$R(T)$ : Confiabilidade em $\mathrm{T}$ horas

e a Probabilidade de Falha pode ser definida como

$$
P(T)=1-R(T)(3) \text {, onde }
$$

$P(T)$ : Probabilidade de Falha em T horas

\section{Consideraçóes importantes}

Para a realização da análise de confiabilidade dos motores em estudo, se fizeram necessários análise e tratamento dos resultados das análises dos lubrificantes em uso nos mesmos, por um período de aproximadamente cinco anos (janeiro de 2005 a março de 2010), comparando seus níveis de desgaste com os respectivos limites aceitáveis, atribuindo-os ao tempo de uso de cada motor. Foram considerados como dados em suspensão os resultados de desgaste que se encontram dentro dos limites máximos permissíveis, e como falhas aqueles resultados que se encontram fora dos referidos limites, tanto para a Parte Alta quanto para a Parte Baixa dos motores.

Outra premissa importante está relacionada com as técnicas de manutenção adotadas. Em todos os dados analisados, considerou-se que os lubrificantes utilizados apresentam alto desempenho e especificamente desenvolvidos para cada aplicaçáo, e não influenciaram nos resultados de vida dos motores, assim como as técnicas de manutenção, que foram aplicadas com os mesmos critérios de intervençáo em todos os casos.
Além disso, para que se possa realizar a comparação dos motores em termos de desempenho sob o ponto de vista de confiabilidade e manutenção, foram escolhidos dois tipos específicos de motores, com dimensóes e potências semelhantes, porém com princípio de funcionamento diferente, mas aplicados em mesmas condiçóes operacionais, ou seja, embarcaçóes do tipo PSV.

\section{Análise de Dados}

Com base nas observaçóes expostas acima, foi possível identificar para cada subsistema, com o auxílio de software específico para esta finalidade, às distribuiçôes do comportamento das falhas e da duração das mesmas, com base nos conceitos e propriedades oriundas da Teoria de Máxima Verossimilhança para a definição dos Parâmetros de Estimação das mesmas, ajustando-as a Distribuição de Weibull.

Além disso, utilizaram-se os conceitos de Matriz de Fischer para a definição dos intervalos de confiança, considerando como premissa que a probabilidade de que os valores reais dos estimadores estejam dentro do intervalo proposto seja de $95 \%$ bilateralmente à distribuição.

A tabela 3 apresenta os parâmetros das distribuiçóes para cada subsistema do equipamento, quando aplicável, de acordo com Reliasoft [6].

Tabela 3 - Parâmetros das Distribuiçôes de Weibull

\begin{tabular}{|c|c|c|c|c|c|c|}
\hline Especificação & \multicolumn{3}{|c|}{ Parte Alta } & \multicolumn{3}{c|}{ Parte Baixa } \\
\cline { 2 - 7 } do Motor & $\beta$ & $\gamma$ & $\eta$ & $\gamma$ & $\eta$ \\
\hline $\begin{array}{c}\text { Caterpillar } \\
\text { MAK 9M-20 }\end{array}$ & 2,23 & 0 & 133.057 & 0,74 & 0 & 608.330 \\
\hline $\begin{array}{c}\text { General } \\
\text { Motors EMD } \\
16 \text { 645E7 }\end{array}$ & 10,57 & 0 & 71.018 & 10,26 & 0 & 68.873 \\
\hline
\end{tabular}

Através dos resultados iniciais é possível observar claramente a condição de final de vida útil (taxa de falhas crescente) para os motores General Motors, tanto para a parte alta quanto para a parte baixa dos motores, sugerindo a necessidade de realização de intervençôes nestes componentes para adequação da taxa de falhas.

No entanto, esta condição não se torna táo acentuada para os motores Caterpillar. Para estes 
motores, enquanto a parte alta encontra-se com a taxa de falhas crescente (final de vida útil), a parte baixa dos motores ainda apresentam taxa de falhas decrescente. Considerando os limites de confiança estabelecidos, é possível observar que o valor de para a parte baixa destes motores pode ser considerada com tendência a falhas aleatórias $(\beta=1)$.

Além disso, fica evidente também a grande diferença dos fatores de escala $\eta$. De acordo com Reliasoft [5], elevados valores de $\eta$ estáo relacionados a elevadas vidas úteis dos componentes.

As figuras 4, 5, 6 e 7 apresentam as funçóes de confiabilidade de cada subsistema em função do tempo (horas de operação).

Considerando que o tempo de operação médio diário das embarcações é de 18 horas (6570 horas trabalhadas por ano), A tabela 4 apresenta os resultados tempo de operaçáo sem manutenções preventivas nos subsistemas, para uma confiabilidade de 95\%, e os Tempos Médios entre Falhas para cada subsistema.

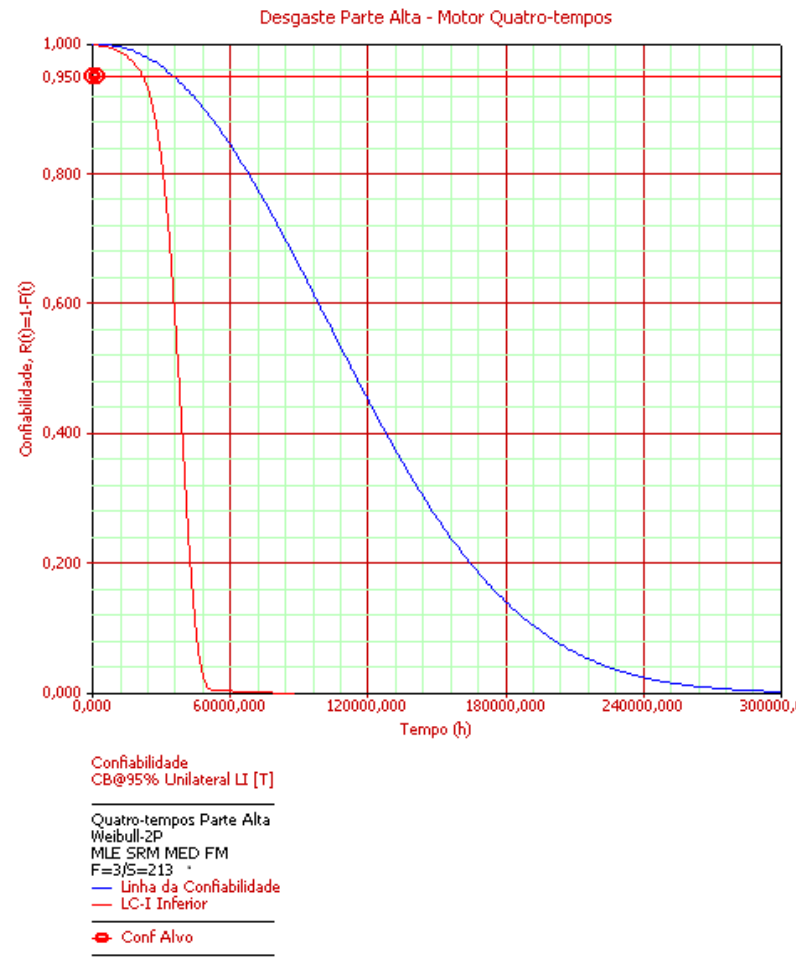

Figura 4 - Função Confiabilidade do Motor Caterpillar - Parte Alta

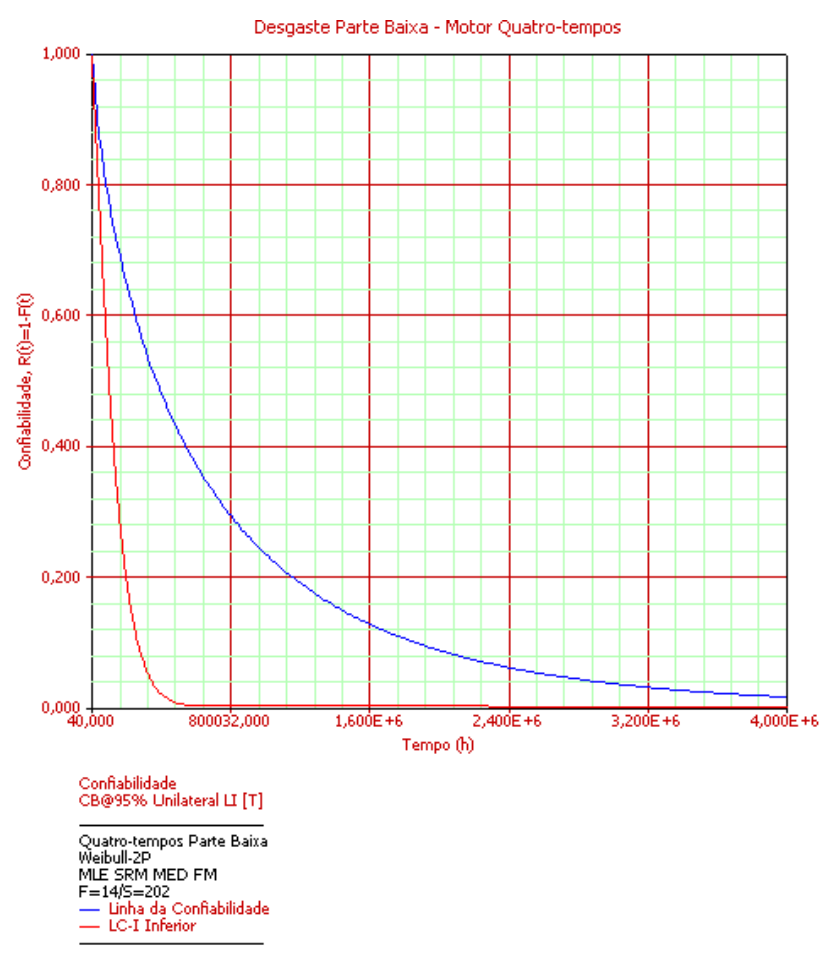

Figura 5 - Função Confiabilidade do Motor Caterpillar - Parte Baixa

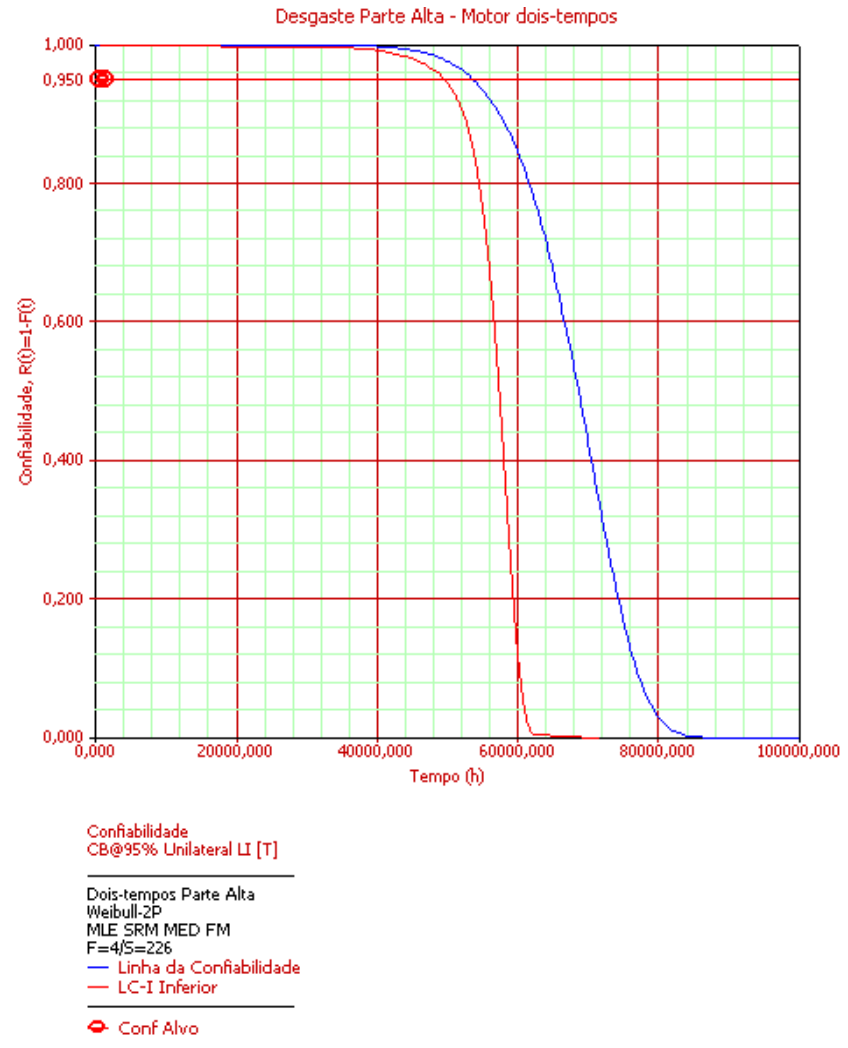

Figura 6 - Função Confiabilidade do Motor General Motors - Parte Alta 


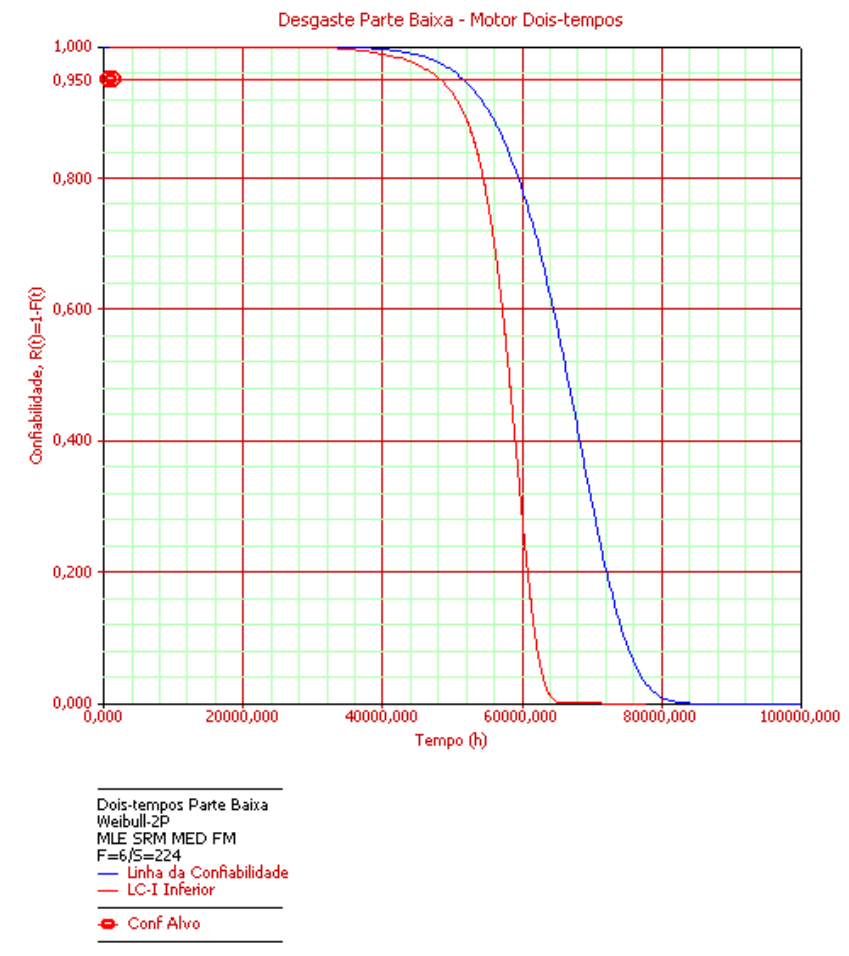

Figura 7 - Função Confiabilidade do Motor General Motors - Parte Baixa

Tabela 4 - Tempo de Operação e Tempo Médio entre Falhas para cada subsistema

\begin{tabular}{|c|l|c|c|}
\hline $\begin{array}{c}\text { Especificação } \\
\text { do Motor }\end{array}$ & Subsistema & $\begin{array}{c}\text { Tempo } \\
\text { para } \\
\mathrm{R}(\mathrm{t})=0,95 \\
\text { (horas) }\end{array}$ & $\begin{array}{c}\text { Tempo } \\
\text { Médio } \\
\text { entre } \\
\text { Falhas } \\
\text { (horas) }\end{array}$ \\
\hline $\begin{array}{c}\text { Caterpillar } \\
\text { MAK 9M-20 }\end{array}$ & Parte Alta & 35.167 & 37.822 \\
\cline { 2 - 4 } & Parte Baixa & 11.275 & 146.950 \\
\hline $\begin{array}{c}\text { General } \\
\text { Motors EMD } \\
\text { 16 645E7 }\end{array}$ & Parte Alta & 53.317 & 57.024 \\
\cline { 2 - 4 } & Parte Baixa & 51.561 & 57.711 \\
\hline
\end{tabular}

Pode-se observar que o fato dos motores General Motors apresentarem $\beta$ elevados implicam em uma maior previsibilidade de falhas, os tempos médios entre falhas dos motores Caterpillar são superiores, devido ao fato de apresentarem seus valores $\eta$ maiores e $\beta$ menores.

\section{MODELAGEM DOS SISTEMAS}

Após a determinação das Distribuiçôes dos subsistemas, é possível realizar a modelagem dos sistemas, utilizando a técnica de Diagrama de Blocos, onde cada bloco corresponde a um subsistema dos motores, sendo o posicionamento dos mesmos em função da condição de projeto do equipamento.

A figura 8 ilustra o Diagrama de Blocos, apresentada por Reliasoft [6], correspondente aos motores das embarcaçóes, compostos pelos subsistemas Parte Alta e Parte Baixa. O modelo para ambos os motores é o mesmo, porém as distribuiçôes de probabilidade de cada subsistema dependem dos parâmetros de cada um.

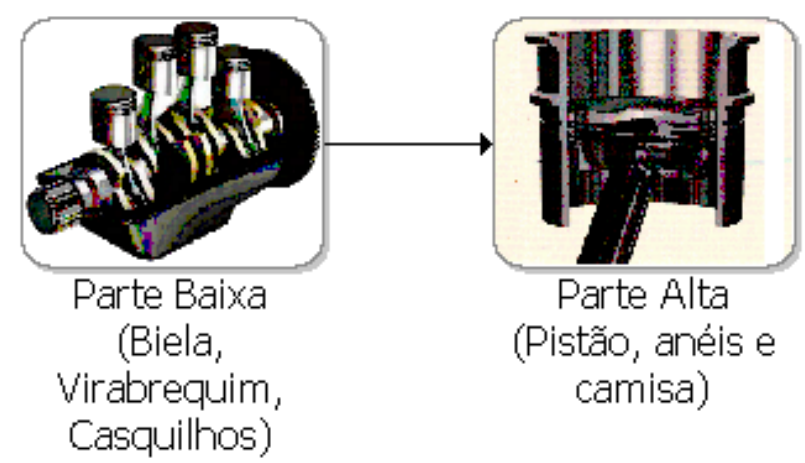

Figura 8 - Diagrama de Blocos dos Motores Caterpillar e General Motors

Através do Diagrama de Blocos dos sistemas é possível obter os gráficos de confiabilidade para cada modelo de motor, os quais estáo sendo apresentados nas Figuras 9 e 10.

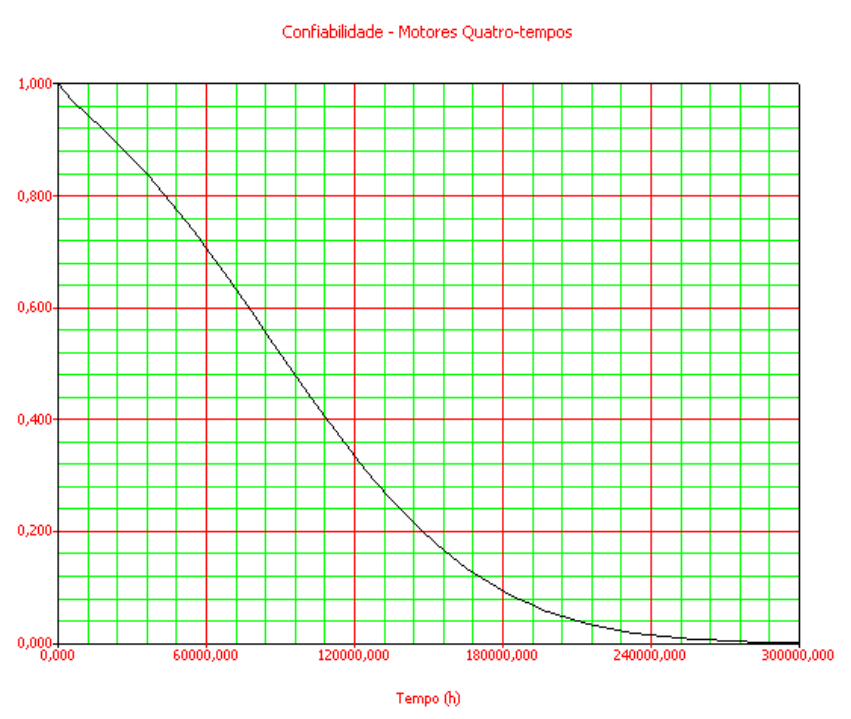

Figura 9-Confiabilidade x Tempo - Motores Caterpillar 


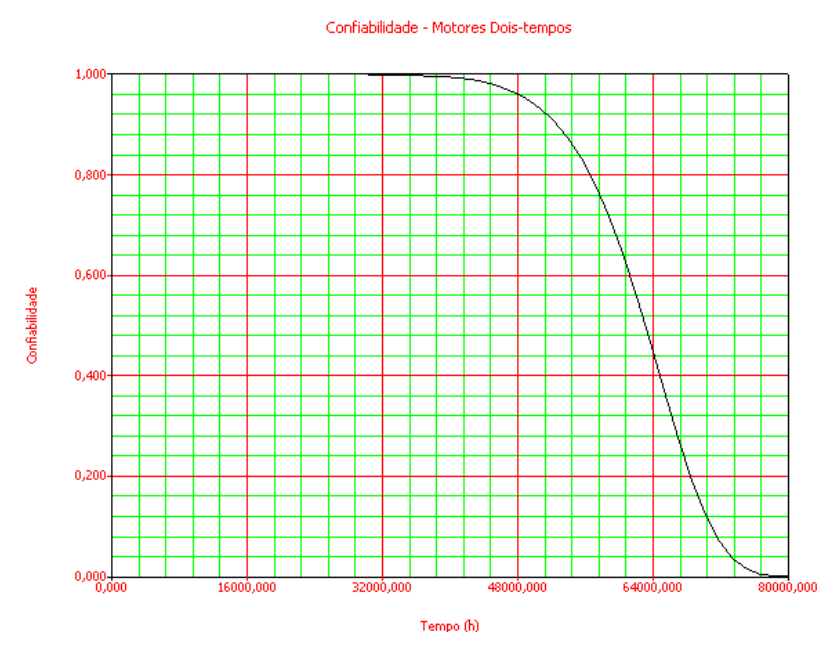

Figura 10 - Confiabilidade x Tempo - Motores General Motors

\section{RESULTADOS E DISCUSSÃO}

Considerando a real necessidade de equipamentos confiáveis durante suas operaçóes, a comparação entre os motores Caterpillar (quatro-tempos) e General Motors (dois-tempos) foi conduzida com foco em confiabilidade requerida, analisando a diferença de desempenho sob o ponto de vista de mantenabilidade.

Para isso, se utilizou como confiabilidade mínima requerida para os equipamentos o valor de $95 \%$, ou seja, espera-se que a probabilidade de ocorrência de desgastes anormais nos motores (parte alta ou parte baixa) em um dado tempo $t$ seja inferior a 5\%. Utilizando este raciocínio, a tabela 5 apresenta os tempos de operação para cada modelo de motor correspondente a confiabilidade de $95 \%$.

Tabela 5 - Tempo de Operação para confiabilidade de $95 \%$

\begin{tabular}{|c|c|c|c|}
\hline $\begin{array}{c}\text { Especificação } \\
\text { do Motor }\end{array}$ & $\begin{array}{c}\text { Ciclo de } \\
\text { funcionamento }\end{array}$ & $\begin{array}{c}\text { Tempo } \\
\text { para } \\
\mathrm{R}(\mathrm{t})=0,95 \\
\text { (horas) }\end{array}$ & $\begin{array}{c}\text { MTBF } \\
\text { (horas) }\end{array}$ \\
\hline $\begin{array}{c}\text { Caterpillar } \\
\text { MAK 9M-20 }\end{array}$ & Quatro-tempos & 10.307 & 97.703 \\
\hline $\begin{array}{c}\text { General } \\
\text { Motors EMD } \\
16 \text { 645E7 }\end{array}$ & Dois-tempos & 49.100 & 62.272 \\
\hline
\end{tabular}

É possível observar a maior previsibilidade de falhas para os motores General Motors em comparação ao motor Caterpillar, o que já era de se esperar em funçáo da análise dos resultados de seus subsistemas apresentados na Tabela 4 .

Além disso, apesar do maior MTBF dos motores Caterpillar em comparaçáo ao General Motors, sua imprevisibilidade de ocorrência das falhas acarreta na redução de confiabilidade e disponibilidade, o que sob o ponto de vista operacional, se torna uma desvantagem considerável.

\section{DEFINIÇÃO DAS ESTRATÉGIAS DE MANUTENÇÃO}

\section{Motor dois-tempos}

Para esta concepção de motor, devido à elevada previsibilidade de falhas, e considerando os resultados obtidos em termos de confiabilidade requerida e MTBF, pode-se representar qualitativamente o comportamento da vida útil dos equipamentos de acordo com a Figura 10.

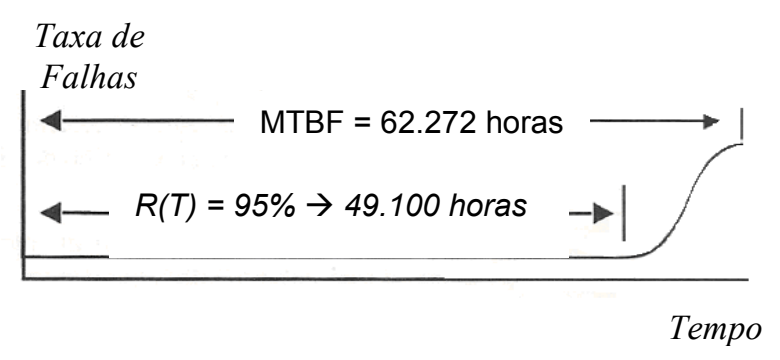

Figura 10 - Comparação entre MTBF e "Vida útil” para motores dois-tempos

Analisando sob o ponto de vista de degradação, e com o objetivo de determinar o intervalo adequado para o monitoramento do equipamento através de análise de óleo, determinou-se como tempo para a falha o tempo correspondente a vida útil estipulada na Figura 10. A partir dessa definição, de acordo com ALADON [1], o intervalo entre monitoramentos deve ser de no máximo um terço do período entre a detecção da falha e a ocorrência da mesma.

Considerando este aspecto, o intervalo entre amostragens do lubrificante para acompanhamento náo deverá ser superior a 16.367 horas de operação. É evidente que o lubrificante não alcançará essa vida útil, e nos casos onde a substituição do lubrificante ocorre em funçáo do tempo, o acompanhamento dos níveis de desgaste do motor através da análise deve ser realizado observando esta condiçáo. A Figura 11 apresenta de maneira qualitativa esta condição, através do 
diagrama P-F.

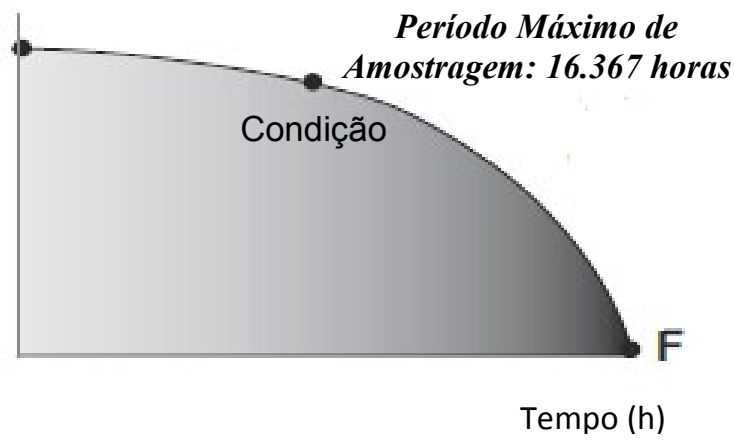

Figura 11 - Diagrama P-F para motores doistempos

Para empresas que monitoram a vida do lubrificante através da análise do mesmo, os intervalos de amostragem sáo inferiores ao exposto acima, e poderão ser utilizados para o acompanhamento dos níveis de desgaste dos motores.

Quando evidenciado, através da análise, desgastes anormais no motor, uma ação que vem sendo adotada é a realização da inspeção interna do equipamento através de Videoscopia, visando identificar a origem do desgaste internamente ao equipamento, e assim poder planejar a parada do equipamento para a intervenção de maneira precisa. Essa ação minimiza os custos de manutenção, pelo fato de saber onde atuar durante a intervenção, além de diminuir o tempo de parada do equipamento.

Se por outro lado, os motores não apresentam monitoramento preditivo, uma estratégia de manutençáo preventiva sistemática que pode ser adotada nesse caso é a parada do motor para recondicionamento em intervalos regulares a cada 50.000 horas, além das demais açóes de manutenção recomendadas nos manuais dos fabricantes dos motores.

\section{Motor quatro-tempos}

A mesma análise foi realizada para os motores quatro-tempos, considerando os resultados obtidos em termos de confiabilidade requerida e MTBF. A Figura 12 representa qualitativamente o comportamento da vida útil dos equipamentos.

Da mesma forma que para os motores dois-tempos, com o objetivo de determinar o intervalo adequado para o monitoramento do equipamento através de análise de óleo, determinaram-se como tempo para a falha o tempo correspondente a vida útil estipulada na figura 12 .
Taxa de

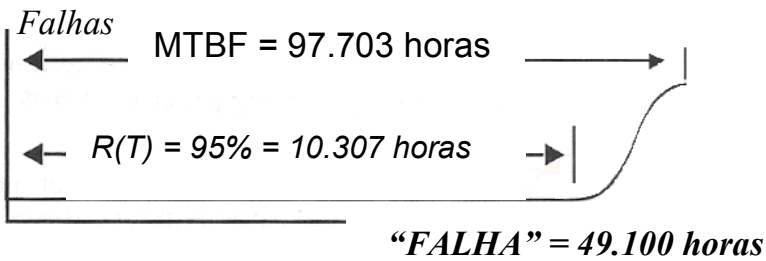

Figura 12 - Comparação entre MTBF e "Vida útil" para motores quatro-tempos

Considerando este aspecto, o intervalo entre amostragens do lubrificante para acompanhamento não deverá ser superior a 3.434 horas de operação. A Figura 13 apresenta de maneira qualitativa esta condição, através do diagrama P-F.

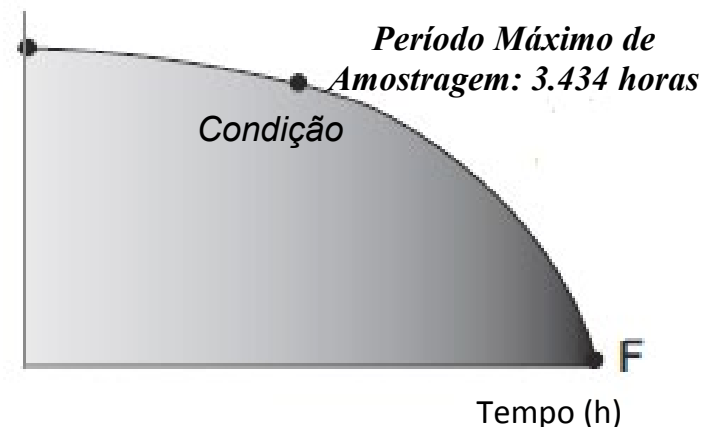

Figura 13 - Diagrama P-F para motores doistempos

Para empresas que monitoram a vida do lubrificante através da análise do mesmo, os intervalos de amostragem poderáo ser utilizados para o acompanhamento dos níveis de desgaste dos motores, desde que sejam menores que o intervalo acima exposto.

Devido ao fato de que a Parte Baixa destes motores estarem em fase de vida útil com taxa de falhas praticamente constante, a ocorrência de falhas aleatórias exige que o monitoramento seja realizado em intervalos curtos, o que implica em maiores despesas no que tange ao monitoramento do equipamento, em comparação ao motor dois-tempos.

Quando evidenciado, através da análise, desgastes anormais no motor, da mesma forma que para os motores dois-tempos, a medida sugerida é a realizaçáo da inspeção interna do equipamento através de Videoscopia, visando identificar a origem do desgaste internamente ao equipamento, e assim poder planejar a parada do equipamento para a intervenção de maneira precisa. 
Para esta concepçáo de motor, devido à aleatoriedade na ocorrência das falhas, não se torna viável a adoção de estratégia de manutenção preventiva sistemática.

\section{CONCLUSÓES}

Considerando o aspecto durabilidade e tempo médio entre falhas, foi possível constatar que os motores quatro-tempos apresentam maior vida útil que os motores dois-tempos. Esta constatação pode estar sustentada a diferença de projeto dos componentes mecânicos.

O fato dos motores dois-tempos estarem expostos a condiçóes mais severas que os quatro-tempos no que tange ao número de explosóes por revoluçáo, promovem aos motores dois-tempos maiores potências mecânicas que os motores quatro-tempos, considerando motores de dimensôes semelhantes, o que pode ser uma vantagem apreciável para os projetistas de embarcações. Por outro lado, deve ser considerado ainda o impacto dos custos com combustíveis e lubrificantes, visto que é sabido que motores dois-tempos apresentam maiores consumos destes insumos, em comparação aos motores quatro-tempos de potências semelhantes, o que implica em maior custo operacional.

Analisando sob o ponto de vista de mantenabilidade, devido ao fato de que a Parte Baixa dos motores quatro-tempos se encontram próximas ao final da fase de vida útil, com taxa de falhas praticamente constante, a ocorrência de falhas aleatórias exige que o monitoramento seja realizado em intervalos curtos, o que implica em maiores despesas no que tange ao monitoramento do equipamento, em comparação ao motor dois-tempos.

Um aspecto importante que deve ser considerado está relacionado ao comportamento das taxas de falhas dos motores. Para os motores dois-tempos, a taxa de falhas tende a aumentar após determinado período de tempo, permanecendo próximo de zero para tempos próximos a 25.000 horas de uso, o que implica que para esta concepçáo de motores, a ocorrência de falhas por desgaste mecânico no começo de vida é praticamente nula. Por outro lado, para este mesmo período de tempo de operação, a taxa de falhas para os motores quatro-tempos é substancialmente superior, o que confirma o fato de que a previsibilidade de falhas dos motores dois-tempos é superior em comparação a dos motores quatro-tempos.

Outro aspecto importante a ser apresentado está relacionado ao comportamento da confiabilidade. Enquanto os motores dois-tempos apresentam elevada confiabilidade durante o início de vida útil, os motores quatro-tempos demonstram a queda gradativa da confiabilidade desde o início de operação. Este aspecto, sob o ponto de vista de manutenção, é muito importante, visto a grande necessidade de confiabilidade dos equipamentos em operação, o que permite concluir que, sob este aspecto, o motor dois-tempos é a melhor opção, principalmente na ausência de estratégias de manutenção preditiva.

Algumas açôes podem ser tomadas no intuito minimizar a ocorrência de falhas aleatórias, dentre estas ações, podem-se destacar as seguintes:

- Utilização de Metodologias de Análise e Bloqueio de Falhas, tais como 5 Porquês, Árvore de Falhas, Análise de Modos e Efeitos de Falhas (FMEA), etc., visando evitar a reincidência das falhas ocorridas;

- Implantaçáo de melhorias no equipamento oriundas de problemas de projeto do mesmo;

- Padronização de procedimentos operacionais, no intuito de reduzir possibilidades de falhas aleatórias por erro humano;

- Elaboração de Planos de Manutenção e Lubrificação considerando os modos de falhas dos subsistemas, utilizando ferramentas de confiabilidade (Manutenção Centrada em Confiabilidade - RCM e Lubrificação Centrada em Confiabilidade - RCL).

\section{REFERÊNCIAS}

Aladon, LTD. Maintenance Management. Lutterworth, 1999.

Consultant, I.S. An Introduction to ReliabilityCentered Spares. Lechlade, 2001.

Lafraia, J.R.B. Manual de Confiabilidade, Mantenabilidade e Disponibilidade. Rio de Janeiro, Qualitymark, 2001.

Reliasoft, BlockSim User's Guide. Arizona, Reliasoft Publishing, 2006. 
Reliasoft, Life Data Analysis Reference. Arizona, Reliasoft Publishing, 2006.

Reliasoft, System Analysis Reference - Reliability, Availability and Optimization. Arizona, Reliasoft Publishing, 2006.

Reliasoft, Weibull ++ User's Guide. Arizona, Reliasoft Publishing, 2006.

Silveira, M.M. Introdução ao Apoio Marítimo, Rio de Janeiro, 2002.

Shell, Treinamento de Lubrificaçáo Automotiva, Rio de Janeiro, 2008.

Caterpillar, Marine Engine Selection Guide, London, 2008.

Vaz, L. Motores de Combustáo - Propulsáo de Navios, Pós Graduação em Engenharia de Máquinas Navais e offshore. Rio de Janeiro, 2008.

Alho, A. Sistemas Navais e Offshore, Pós Graduação em Engenharia de Máquinas Navais e offshore. Rio de Janeiro, 2008.

Bocchetti, D.; Giorgio, M.,Guida, M.; Pulcini, G. A competing risk model for the reliability of cylinder liners in marine Diesel engines. Reliability Engineering and System Safety. Italy, 2007.

Louit, D.M.; Pascual, R.; Jardine, A.K.S. A practical procedure for selection of time-to-failure models based on the assessment of trends in maintenance data. Reliability Engineering and System Safety. Chile, 2008.

Artana, K.B.; Ishida, K. Spreadsheet modeling of optimal maintenance schedule for components in wear-out phase. Reliability Engineering and System Safety. Japan, 2008.

Mokashi, A.J.; Wang, J.; Vermar, A.K. A study of reliability-centred maintenance in marine operations. Marine Policy. India, 2002.

Milkie, C.M.; Perakis, A.N. Statistical method for planning Diesel Engine overhauls in the U.S. Coast Guard. Naval Engineering Journal. USA, 2004.

Lamaris, V.T.; Hountalas, D.T. A general purpose diagnostic technique for marine diesel engines - Aplication on the main propulsion and auxiliary diesel units of a marine vessel. Energy Conversion and Management. Greace, 2009. 